Caberletti, Luca; Elfmann, K.; Kummel, M.; Schierz, Christoph:

Influence of ambient lighting in a vehicle interior on the driver's perceptions

URN: $\quad$ urn:nbn:de:gbv:ilm1-2014210239

Published OpenAccess: October 2014

Original published in:

Lighting research and technology. - London [u.a.] : Sage (ISSN 1477-0938). - 42 (2010) 3, S. 297-311.

DOI: $\quad 10.1177 / 1477153510370554$

URL: $\quad$ http://dx.doi.org/10.1177/1477153510370554

[Visited: 2014-10-14]

„Im Rahmen der hochschulweiten Open-Access-Strategie für die Zweitveröffentlichung identifiziert durch die Universitätsbibliothek IImenau."

"Within the academic Open Access Strategy identified for deposition by Ilmenau University Library."

„Dieser Beitrag ist mit Zustimmung des Rechteinhabers aufgrund einer (DFG-geförderten) Allianz- bzw. Nationallizenz frei zugänglich."

"This publication is with permission of the rights owner freely accessible due to an Alliance licence and a national licence (funded by the DFG, German Research Foundation) respectively."

\section{DFG}

Nationallizenzen 


\section{Lighting Research and Technology}

Influence of ambient lighting in a vehicle interior on the driver's perceptions L. Caberletti, K. Elfmann, M. Kummel and C. Schierz

Lighting Research and Technology 2010 42: 297 originally published online 16 August 2010 DOI: $10.1177 / 1477153510370554$

The online version of this article can be found at:

http://Irt.sagepub.com/content/42/3/297

\section{Published by:}

(\$) SAGE

http://www.sagepublications.com

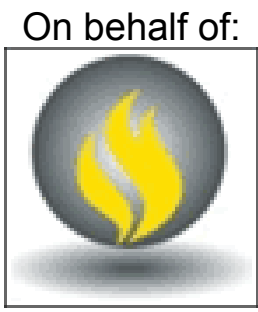

The Society of Light and Lighting

Additional services and information for Lighting Research and Technology can be found at:

Email Alerts: http://rt.sagepub.com/cgi/alerts

Subscriptions: http://Irt.sagepub.com/subscriptions

Reprints: http://www.sagepub.com/journalsReprints.nav

Permissions: http://www.sagepub.com/journalsPermissions.nav

Citations: http://rt.sagepub.com/content/42/3/297.refs.html

>> Version of Record - Sep 10, 2010

OnlineFirst Version of Record - Aug 16, 2010 


\title{
Influence of ambient lighting in a vehicle interior on the driver's perceptions
}

\author{
L Caberletti Ing ${ }^{a}$, K Elfmann Dipl-Ing ${ }^{\mathrm{a}, *}, \mathbf{M}$ Kummel Dr-Ing ${ }^{\mathrm{a}}$ and C Schierz Dr sc nat ${ }^{\mathrm{b}}$ \\ ${ }^{a} B M W$ Group, Knorrstrasse 147, 80788 Munich, Germany \\ bighting Engineering Group, IImenau University of Technology, PF 100565, 98684, Ilmenau, Germany
}

Received 26 January 2010; Revised 15 March 2010; Accepted 31 March 2010

An experimental study on the effects of vehicle ambient lighting on the subjective perception of the driver has been conducted. In an experimental vehicle 12 different ambient interior lighting scenarios were displayed to 31 people while driving in an immersive simulation which created a visual environment similar to a night drive. After each experimental run the driver answered different questions on their perception of the vehicle interior under the different lighting scenarios. The results showed that ambient lighting, although being in a peripheral position in the driver's field of view, has several significant positive influences on space perception, interior attractiveness, perceived safety, functionality and perceived interior quality.

\section{Introduction}

Ambient interior lighting for vehicles is an issue of dramatically growing relevance in the automotive industry. In the last decade the number of light sources in the car interior providing this illumination has drastically increased, up to a current maximum of about 25 LEDs, which is very likely to be exceeded in the next generation of vehicles. A steadily growing number of cars in the high and middle class market segments are equipped with such lighting.

Ambient lighting provides an indirect illumination of the passenger compartment in low light settings, such as during the night. Its importance lies in the fact that it provides a better orientation in the car, an improved sense of spaciousness, as well as an impression of safety, value and comfort. Furthermore it conveys an emotional and brandoriented atmosphere to the otherwise dark

\footnotetext{
* K Elfmann is now at Jordan Reflektoren GmbH \& Co KG, Schwelmer Strasse 161, 42389 Wuppertal, Germany.

Address for correspondence: Luca Caberletti, BMW Group, Knorrstrasse 147, 80788 Munchen, Germany.

E-mail: luca.caberletti@bmw.de
}

car interior at night. Moreover, ambient lighting can harmonise the luminances between the vehicle interior and the external environment, thus decreasing the driver's fatigue when driving at night. ${ }^{1}$ Ambient lighting does not perform a purely functional role and therefore it can be designed in any colour, since it does not require good colour rendering. Indeed, car makers use different colours in order to give a branded image of the car interior.

It is important to note that since ambient lighting is indirect illumination, the materials from which it is reflected acquire new value and quality. Night design thus plays a central role, since the materials and the lines of the car interior are visible not only during daytime but at night too. On the other hand, disability and discomfort glare caused by ambient lighting should be avoided, in order not to impair vision and decrease safety during night driving.

\section{Motivation}

Previous studies by Grimm $^{2}$ proved that disability and discomfort glare originating from 
ambient lighting can be eliminated by keeping the maximum luminance under $0.1 \mathrm{~cd} / \mathrm{m}^{2}$. In this way, negative effects on safety can be removed. Also, studies by Schellinger et al. ${ }^{3}$ and Karsten and Lemmer ${ }^{4}$ stated that the driver's contrast vision will not be negatively affected by ambient lighting, if the driver can control its brightness. Other studies on vehicle interior lighting addressed the issue of possible glare caused by reading lamps or dome lights through veiling luminance and unwanted mirror effects. ${ }^{5,6}$ However, there are no guidelines which indicate how to correctly and consequently arrange ambient lighting in the car interior in order to maximise its positive effects. In fact, this procedure is based nowadays upon experts' personal judgement.

Many studies investigate the effects of lighting on mood, ${ }^{7,8}$ emotions ${ }^{9}$ and perceptions, ${ }^{10,11}$ for lighting design in buildings and in office-environments. Of interest in this study is if such effects can be caused even in the relatively small environment of the vehicle and with such small luminances as occur with ambient lighting.

Thus, in order to fully understand the advantages of ambient lighting in relationship to its characteristics and parameters, an experimental research study has been conducted and is presented in this paper.

\section{Method}

In an immersive virtual test environment, 31 people had the task of 'driving' a real stationary vehicle on a virtual highway. In the vehicle, a different ambient lighting scenario was displayed in each run. In total 12 different scenarios were tested, in which the following parameters were varied: light colour, luminance and position.

\subsection{Experimental setup}

The test took place in a static driving simulator at the BMW Group research centre. ${ }^{12}$
By using a simulator rather than driving on real streets, complete control of the environmental variables was achieved which guaranteed the repeatability of the experiment and thus increased the reliability of the results.

A BMW 3 Series equipped with special interior light features was used for the experiment. It was connected to the simulator in a way that allowed the driver to steer the car but not to accelerate or brake (a collision with the preceding vehicle was impossible because of the control mechanisms in the driving simulation software). The driving simulation was projected on three screens placed in front and around the car so that they covered a viewing angle of about $135^{\circ}$. In the simulator room, an ambient luminance between $0.01 \mathrm{~cd} / \mathrm{m}^{2}$ and $0.1 \mathrm{~cd} / \mathrm{m}^{2}$ was present, which ensured mesopic visual adaptation. The luminance on the simulated street lane was between $0.1 \mathrm{~cd} / \mathrm{m}^{2}$ and $1.5 \mathrm{~cd} / \mathrm{m}^{2}$, a range of values which matches the recommended ${ }^{13,14}$ as well as measured street luminances. ${ }^{15-17}$

\subsection{Participants}

The investigation took place with 31 participants, 8 women and 23 men, between 21- and 58 -years old (mean age 35 years). Eighteen of them had already experienced ambient lighting while driving. 14 of them wore glasses or contact lenses. For each participant the experiment lasted 1.5 to 2 hours.

\subsection{Procedure}

After carrying out the Ishihara Colour Vision Test ${ }^{18}$ (all the participants had a good colour vision) the room was darkened. The participants had 10 minutes for dark adaptation. During this time the investigator described the objectives and the methods of the research. Afterwards the participants drove the vehicle a few minutes on the simulator in order to become familiar with the feel of the steering. After this period of adaptation the test started. 
The investigator sat in a separate room and communicated with the driver through a radio. After he started the simulation, the vehicle accelerated to $100 \mathrm{~km} / \mathrm{h}$ and then remained at this speed. During the acceleration the appropriate lighting scene was activated and then maintained for 3 minutes. Meanwhile, the driver drove according to the main task, which was to follow a car on the right highway lane. Since the attention of the driver was focused on the driving task, the ambient lighting was only perceived peripherally, as in reality.

Each minute the driver was asked to accomplish a secondary task. The aim of these tasks was to give the driver the possibility of evaluating the extent to which the current lighting situation helped or hindered some of the normal actions that take place while driving. Typical secondary tasks were the adjustment of the climate ventilation nozzles or the finding and operation of a specific control button. When the driver was unable to accomplish the secondary task, he was allowed to refuse it.

After 3 minutes, the ambient lighting was turned off and the vehicle was stopped by the investigator and brought onto the side-strip. The simulation carried on, as in a normal traffic situation. The participants then completed the questionnaire relating to the perceived lighting scenario. To allow this activity the driver's reading lamp was dimmed on. Its brightness was chosen to be as low as possible in order not to change the driver's adaptation level, but still high enough to guarantee an adequate readability of the questionnaire (10lux measured at the reading point, $15 \mathrm{~cm}$ above the driver's knees). Since the aim of the experiment was to collect the impressions of the driver while focused on the driving task, ambient lighting was turned off during the filling out of the questionnaire. In this way, the perception gained during the actual experimental run was not influenced by possible different aspects noticed or discovered during the stop. Contrarily, the lighting scenario displayed in the stop situation was clearly acknowledged as not to be assessed. Moreover, the questionnaire was posed during a stop in order not to influence the driving performance.

The whole process was repeated with all 12 lighting scenarios which were presented in random order to each test person.

\subsection{Ambient lighting scenarios}

In the test vehicle, which was provided with a brown leather interior and black plastic trims, 12 different ambient lighting scenarios were realised (Table 1). Three parameters were varied: colour, position of the light sources and luminance, as described in Table 2.

The lighting colours presented in the test were orange and blue, with dominant wavelengths of $605 \mathrm{~nm}$ and $471 \mathrm{~nm}$ respectively. The spectra of the LEDs mounted on the experimental vehicle are shown in Figure 1. Each light fixture was provided with both colours.

Lighting positions were selected from among those commonly used in practice in the automotive industry (Figure 2). The centre console light consisted of two LEDs hidden inside the roof node and illuminated the centre

Table 1 Description of the tested ambient lighting scenarios. Scenarios 1 to 11 provided orange lighting, while scenario 12 used blue lighting

\begin{tabular}{ll}
\hline Number & Lighting scenario \\
\hline 1 & Everything on - bright level with accents \\
2 & Series (Centre console + Door trims) \\
3 & Doors - bright level \\
4 & Doors - low level \\
5 & Without ambient lighting \\
6 & Everything on - bright level \\
7 & Everything on - low level \\
8 & Everything on - middle level \\
9 & Foot space - bright level \\
10 & Foot space - low level \\
11 & Centre console \\
12 & Everything on blue - low level \\
\hline
\end{tabular}


console area, where usually the gear selector lever and the controls for entertainment and conditioning are placed. Foot space lighting was realised with two LEDs placed inside

Table 2 Experimental parameters. Areas are considered illuminated by ambient lighting only when their luminance lies between 0.003 and $0.5 \mathrm{~cd} / \mathrm{m}^{2}$

\begin{tabular}{ll}
\hline Parameter & States \\
\hline Colour & Orange $(605 \mathrm{~nm})$ \\
Position & Blue $(471 \mathrm{~nm})$ \\
& Centre console only \\
& Doors only \\
& Foot space only \\
& Series (Centre console + \\
& door trims) \\
& Complete $($ Centre console + \\
& doors + foot space) \\
& Bright (more than $\left.0.04 \mathrm{~cd} / \mathrm{m}^{2}\right)$ \\
Mean luminance over & Middle $\left(0.02-0.01 \mathrm{~cd} / \mathrm{m}^{2}\right)$ \\
the illuminated area & Low level $\left(0.007 \mathrm{~cd} / \mathrm{m}^{2}\right)$ \\
& \\
\hline
\end{tabular}

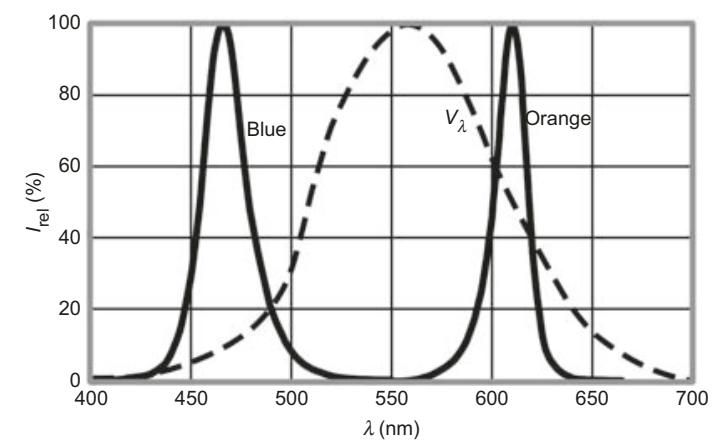

Figure 1 Spectra of the two LEDs used in the experimental car: blue and orange ${ }^{19}$

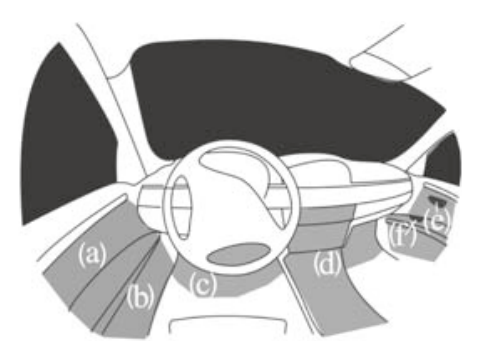

Figure 2 Positions of the ambient lighting. (a) door trim, (b) map case, (c) foot space, (d) centre console. With (e) and (f) the accents on the right door are highlighted (door handle and door pull respectively) the cockpit facing downwards, illuminating the pedal area, on both the driver and passenger sides. The illumination of each door consisted of two modules, each composed of one LED feeding a linear light guide which distributed the light homogeneously from its side. One of these modules illuminated the upper part (door trims), the other illuminated the lower part (map case) of the door. Both modules where hidden under specific gaps in the geometry of the door and integrated into its design. Their combination provided a homogeneous coverage of the whole door zone. All light sources were hidden from the driver's view so that the ambient lighting was perceived only through the reflection on the interior surfaces.

The particular combination of door trim lighting and centre console lighting is a common setting in series-production vehicles of different car manufacturers and therefore was named series lighting. The setting 'everything on' included all the above-mentioned lighting fixtures properly adjusted so that they could provide a homogeneous appearance. The setting 'everything bright - with accents' provided a few additional points (door handles and door pulls, each illuminated respectively with one LED) with higher luminances (up to $2 \mathrm{~cd} / \mathrm{m}^{2}$ ).

Cockpit instruments and backlit symbols were always turned on, as in a real night driving situation. It could be argued that the perception of ambient lighting and of the whole car interior is influenced by the instrumentation lighting and its reflections. In order to solve this problem, the luminance of these elements was kept constant during the study. This luminance was chosen to be the middle value in the range of the series-production settings. The navigation system display was turned on and showed a constantly blank screenshot. An example of an ambient lighting scenario and its interaction with the instrumentation lighting is provided in Figure 3. 


\subsection{Luminance measurements}

The luminances of the areas illuminated by the ambient lighting fixtures in the vehicle were measured using a luminance camera provided with fish-eye optic (LMK Mobile Advanced, TechnoTeam, Ilmenau / Germany). In this way, the brightness in the whole field of view could be measured from the driver's perspective. The visual field has been divided into four zones (Figure 4). In these four zones, only the measurement points with a photopic luminance between $0.003 \mathrm{~cd} / \mathrm{m}^{2}$ and $0.5 \mathrm{~cd} / \mathrm{m}^{2}$ have been considered. These areas can be considered to be illuminated by ambient lighting. Luminances below $0.003 \mathrm{~cd} / \mathrm{m}^{2}$ have been considered dark, while those above $0.5 \mathrm{~cd} / \mathrm{m}^{2}$ have been considered symbol lighting, and so not to be measured together with the ambient lighting. In Table 3, the mean luminances $L_{\mathrm{M}}$ for these areas are displayed.

Since the lit area changes with the intensity of the illumination, the solid angle under which the area is seen by the driver $(\Omega)$ has also been calculated. The product of the solid angle and the mean luminance $L_{\mathrm{M}} \Omega$ for each considered zone, displayed in Table 4 , gives

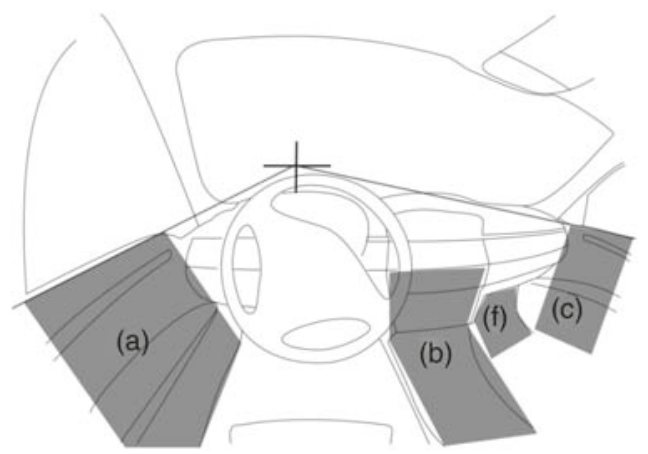

Figure 4 Luminance measurement zones. (a) left door; (b) centre console; (c) right door; (f) foot space

Table 3 Mean luminance $L_{M}$ for the different measurement zones and the different ambient lighting scenarios $\left(\mathrm{cd} / \mathrm{m}^{2}\right)$

\begin{tabular}{lllllll}
\hline Scenario & 1 & 2 & 3 & 4 & 5 & 6 \\
\hline A & 0.023 & 0.009 & 0.023 & 0.022 & - & 0.023 \\
B & 0.012 & 0.011 & 0.009 & - & - & 0.010 \\
C & 0.023 & 0.006 & 0.029 & 0.017 & - & 0.026 \\
F & 0.008 & - & - & - & - & 0.008 \\
\hline Scenario & 7 & 8 & 9 & 10 & 11 & 12 \\
\hline A & 0.021 & 0.015 & - & - & - & 0.028 \\
B & 0.008 & 0.010 & - & - & 0.010 & 0.013 \\
C & 0.017 & 0.017 & - & - & - & 0.016 \\
F & - & - & 0.008 & 0.004 & - & -
\end{tabular}

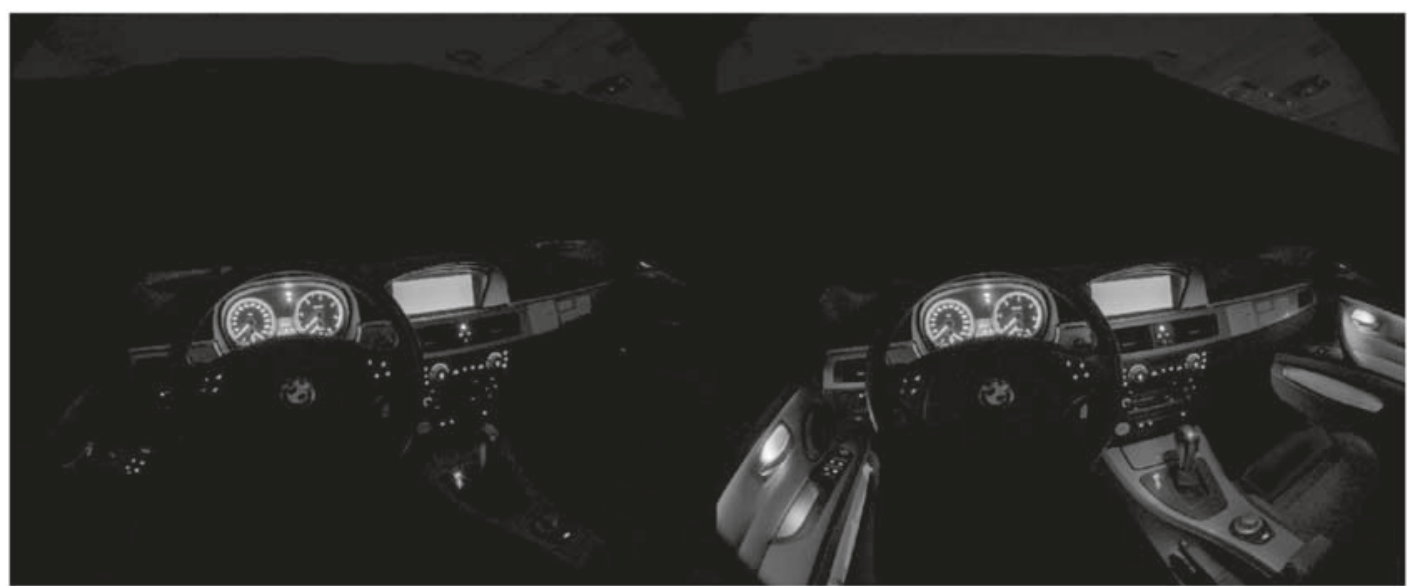

Figure 3 Experimental vehicle interior. Scenes without any ambient lighting (left) and with an ambient lighting scenario provided with centre console and door illumination, including door handles and door pulls (right). The instrumentation lighting is always turned on at a constant luminance. The display in the centre is on, showing a constant blank screen 
Table 4 Eye illuminances (measured in the area's direction) $\left(L_{\mathrm{M}} \Omega\right)$ for the different measurement zones and the different ambient lighting scenarios $\left(10^{-3} \mathrm{~cd} \cdot \mathrm{sr} / \mathrm{m}^{2}\right)$

\begin{tabular}{lllllll}
\hline Scenario & 1 & 2 & 3 & 4 & 5 & 6 \\
\hline A & 3.17 & 0.65 & 2.60 & 0.62 & - & 2.64 \\
B & 0.71 & 0.50 & 0.04 & 0.03 & 0.02 & 0.54 \\
C & 1.11 & 0.05 & 0.91 & 0.31 & - & 0.92 \\
F & 0.27 & - & - & - & - & 0.27 \\
\hline Scenario & 7 & 8 & 9 & 10 & 11 & 12 \\
\hline A & 0.63 & 1.41 & 0.01 & - & - & 0.86 \\
B & 0.13 & 0.49 & 0.03 & 0.03 & 0.48 & 0.69 \\
C & 0.31 & 0.48 & 0.01 & - & - & 0.37 \\
F & 0.05 & 0.05 & 0.26 & 0.04 & - & 0.01 \\
\hline
\end{tabular}

the illuminance at the eye, measured in the direction of the area.

Cockpit lighting as well as backlit symbols have not been considered in these measures, since they did not vary in luminance throughout the whole experiment.

\subsection{Questionnaire}

\subsubsection{Subjective perception of the lighting}

After each experimental run, each driver was asked to fill out a questionnaire in the form of 18 semantic differential pairs, which were arranged to cover the following aspects: space perception, perceived interior quality, interior attractiveness, perceived safety, alertness and functionality.

The questions were the following: The displayed light situation...

- Space perception ... allows the perception of the whole car interior/does not allow the perception of the whole car interior; ... causes a small impression of interior space/ causes a big impression of interior space.

- Perceived interior quality ... looks cheap/ looks luxurious; ... gives a lesser quality impression/gives a good quality impression.

- Interior attractiveness ...has a really unpleasant light colour/...has a really pleasant light colour; ... is too dark/is too bright; ...appears pleasant/appears unpleasant; ... is comfortable/is uncomfortable; ... I really liked/I really disliked.

- Perceived safety ... increases the perceived safety/decreases the perceived safety.

- Functionality ... enables a better orientation in the car interior/complicates the orientation in the car interior; ... facilitates the finding of controls/complicates the finding of controls; ... makes me more powerful/ makes me less powerful; ... causes distracting reflections in the windshield/does not cause reflections in the windshield;

- Alertness ...distracts me from driving/ keeps my attention on the driving; ... complicates concentration/enables concentration; ...makes me tired/activates me; ... makes me sleepy/animates me.

The questions, listed also in Table 5, were presented in random order and so arranged that the positive sentences were equally distributed on both sides of the questionnaire.

The answers were given by the driver on a continuous scale with a vertical line signalling the middle, as represented in Figure 5.

\subsubsection{Emotional state}

The influences of the three lighting parameters on the emotional state of the drivers were also researched, using a self-assessment manikin (SAM) procedure. ${ }^{20}$ This method, displayed in Figure 6, consists of a non-verbal graphic questionnaire based on the PleasureArousal-Dominance (PAD) model, ${ }^{21,22}$ which has been already adopted to describe the emotional state caused by colours ${ }^{23}$ and lighting situations. ${ }^{9,24}$ The SAM has been chosen since it can be answered in a shorter time than other methods for assessing emotional states, like the Semantic Differential Scale devised by Mehrabian and Russell, ${ }^{21}$ which consists of 18 bipolar adjective pairs. Nonetheless, the results acquired with this simple method hold a strong correlation to the results obtained through more complex tests. ${ }^{25}$ 
Table 5 Semantic differential pairs posed in the questionnaire. The ratings were given on a continuous line running from 0 to 1 with the midpoint marked (Figure 5)

\begin{tabular}{lll}
\hline $\begin{array}{l}\text { The displayed light situation ... } \\
\text { Question } \\
\text { number }\end{array}$ & Element (0) & Element (1) \\
\hline 1 & $\begin{array}{l}\text { Causes a small impression of interior space } \\
\text { Does not allow the perception } \\
\text { of the whole car interior } \\
\text { Has a really unpleasant light colour }\end{array}$ & $\begin{array}{l}\text { Causes a big impression of interior space } \\
\text { Allows the perception of the } \\
\text { whole car interior }\end{array}$ \\
3 & I really disliked & Has a really pleasant light colour \\
4 & Is too dark & Is too bright \\
5 & Appears unpleasant & Appears pleasant \\
6 & Is uncomfortable & Is comfortable \\
7 & Gives a lesser quality impression & Gives a good quality impression \\
8 & Looks cheap & Looks luxurious \\
9 & Makes me less powerful & Makes me more powerful \\
10 & Complicates orientation in the car interior & Enables better orientation in the car interior \\
11 & Complicates the finding of controls & Facilitates the finding of controls \\
12 & Causes distracting reflections & Does not cause reflections \\
13 & in the windshield & in the windshield \\
& Distracts me from driving & Keeps my attention on the driving \\
14 & Complicates concentration & Anables concentration \\
15 & Makes me tired & Activates me \\
16 & Makes me sleepy & Animates me \\
17 & Decreases the perceived safety & Increases the perceived safety \\
18 & &
\end{tabular}

\begin{tabular}{|c|c|c|}
\hline $\begin{array}{l}\text { Causes distracting } \\
\text { reflections in the } \\
\text { windshields }\end{array}$ & 1 & $\begin{array}{l}\text { Does not cause } \\
\text { reflections in the } \\
\text { windshields }\end{array}$ \\
\hline Is comfortable & I & Is uncomfortable \\
\hline $\begin{array}{l}\text { Increases the perceived } \\
\text { safety }\end{array}$ & 1 & $\begin{array}{l}\text { Decreases the } \\
\text { perceived safety }\end{array}$ \\
\hline Makes me sleepy & I & Activates me \\
\hline $\begin{array}{l}\text { Facilitates the finding of } \\
\text { controls }\end{array}$ & 1 & $\begin{array}{l}\text { Complicates the finding } \\
\text { of controls }\end{array}$ \\
\hline Looks luxurious & 1 & Looks cheap \\
\hline
\end{tabular}

Figure 5 Example of the differential pairs questionnaire

The three independent dimensions pleasure, arousal and dominance are assessed separately, by checking the circle under the manikin which the driver feels matches his or her state. The pleasure dimension spans from happy, content (corresponding to 1 on its scale) to unhappy, displeased (9). Arousal mirrors the activity of the person, ranging from agitated, wide awake and aroused (1) to sleepy, calm and inactive (9). Dominance 

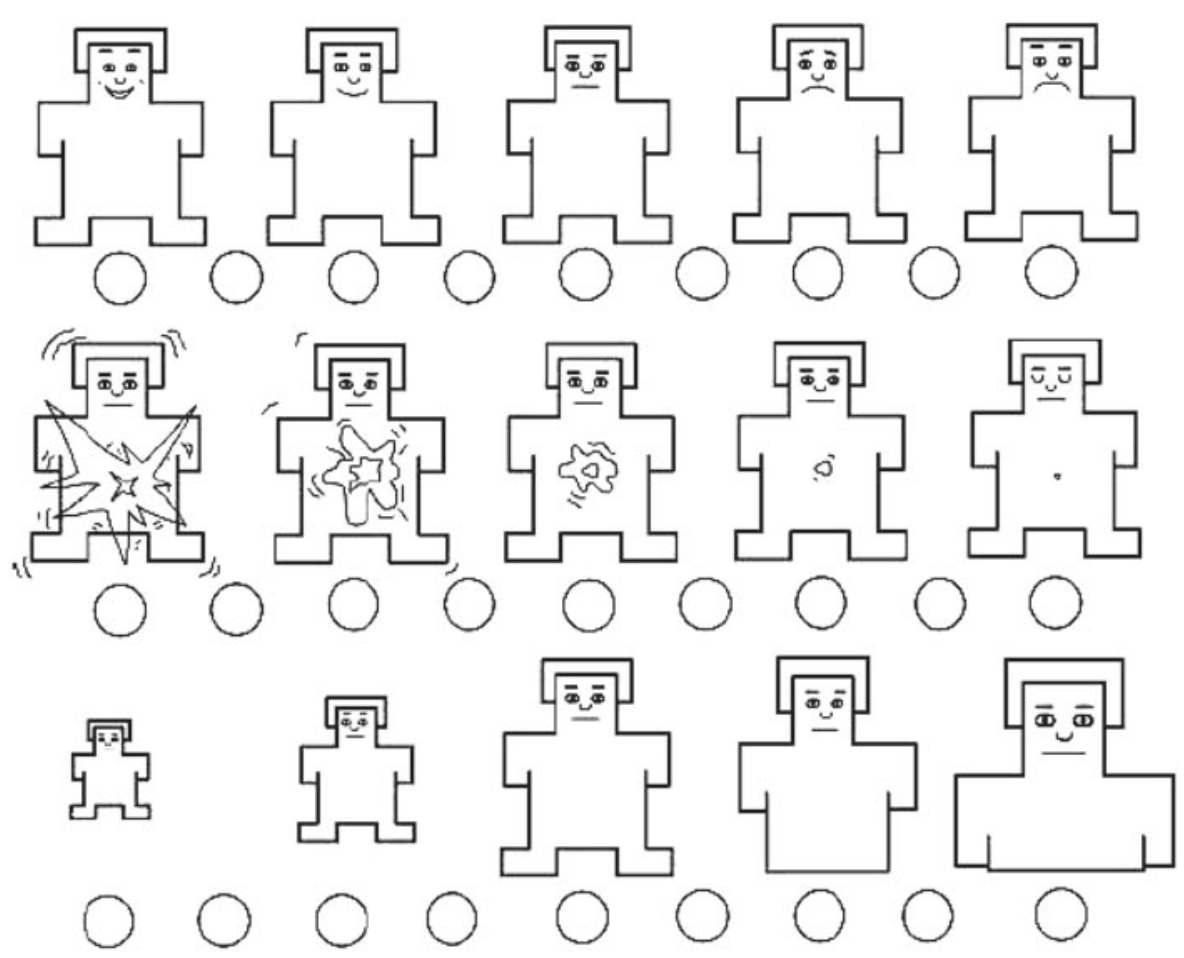

Figure 6 Self-Assessment Manikin questionnaire. ${ }^{20}$ The three manikin rows refer to the pleasure, arousal and dominance dimensions, from top to bottom

states if a person feels controlled (1) or rather in command of the situation (9).

The drivers were asked to fill out this form at the beginning of the test (in order to know the emotional state at the starting point) and after each experimental run.

\section{Results}

\subsection{Subjective perception of the car interior}

In the following, the results of the questionnaire on the subjective perceptions will be displayed. The mean ratings of each scenario for each question, as well as their standard deviations are listed in Table 6. Different scenarios were compared in order to understand the influence of each parameter: brightness, position and colour of the lighting. The significance levels of each comparison are listed in Table 7. The statistical significance of the results was assessed using a Wilcoxon test for two related samples of nonparametric data. No significant differences originated from differences in the test person's gender or age.

\subsubsection{Effects of brightness}

The effects of luminance variations were verified by comparing the following settings: without lighting - everything on low level everything on bright level with accents (scenarios $5-7-1$ ).

The comparison between the scenarios 'without lighting' and the 'everything on low level' showed highly significant $(p<0.01)$ improvements for the five aspects: space perception, interior attractiveness, functionality, perceived interior quality and perceived safety. Regarding the aspect alertness, no significance could be found: no degradation could be seen either. 
Table 6 Results of subjective research. For each ambient lighting scenario is listed the means and associated standard deviations obtained for each question

\begin{tabular}{|c|c|c|c|c|c|c|c|c|c|c|c|c|}
\hline \multirow[b]{2}{*}{$\begin{array}{l}\text { Qu. } \\
\text { No. }\end{array}$} & \multicolumn{2}{|c|}{ Scenario 1} & \multicolumn{2}{|c|}{ Scenario 2} & \multicolumn{2}{|c|}{ Scenario 3} & \multicolumn{2}{|c|}{ Scenario 4} & \multicolumn{2}{|c|}{ Scenario 5} & \multicolumn{2}{|c|}{ Scenario 6} \\
\hline & Mean & $\begin{array}{l}\text { Std. } \\
\text { dev. }\end{array}$ & Mean & $\begin{array}{l}\text { Std. } \\
\text { dev. }\end{array}$ & Mean & $\begin{array}{l}\text { Std. } \\
\text { dev. }\end{array}$ & Mean & $\begin{array}{l}\text { Std. } \\
\text { dev. }\end{array}$ & Mean & $\begin{array}{l}\text { Std. } \\
\text { dev. }\end{array}$ & Mean & $\begin{array}{l}\text { Std. } \\
\text { dev. }\end{array}$ \\
\hline 1 & 0.62 & 0.16 & 0.61 & 0.16 & 0.57 & 0.13 & 0.54 & 0.17 & 0.42 & 0.17 & 0.55 & 0.14 \\
\hline 2 & 0.66 & 0.20 & 0.56 & 0.18 & 0.50 & 0.18 & 0.50 & 0.18 & 0.25 & 0.16 & 0.61 & 0.18 \\
\hline 3 & 0.62 & 0.17 & 0.68 & 0.14 & 0.64 & 0.17 & 0.63 & 0.11 & 0.54 & 0.09 & 0.64 & 0.16 \\
\hline 4 & 0.49 & 0.26 & 0.67 & 0.18 & 0.50 & 0.19 & 0.57 & 0.12 & 0.38 & 0.14 & 0.57 & 0.19 \\
\hline 5 & 0.75 & 0.16 & 0.44 & 0.10 & 0.61 & 0.18 & 0.47 & 0.08 & 0.32 & 0.16 & 0.60 & 0.18 \\
\hline 6 & 0.47 & 0.20 & 0.66 & 0.15 & 0.53 & 0.18 & 0.59 & 0.12 & 0.47 & 0.09 & 0.57 & 0.18 \\
\hline 7 & 0.46 & 0.18 & 0.67 & 0.15 & 0.55 & 0.18 & 0.59 & 0.14 & 0.45 & 0.15 & 0.57 & 0.16 \\
\hline 8 & 0.57 & 0.24 & 0.68 & 0.18 & 0.59 & 0.16 & 0.57 & 0.13 & 0.44 & 0.14 & 0.63 & 0.17 \\
\hline 9 & 0.58 & 0.19 & 0.67 & 0.18 & 0.59 & 0.15 & 0.61 & 0.13 & 0.45 & 0.13 & 0.63 & 0.15 \\
\hline 10 & 0.48 & 0.18 & 0.52 & 0.12 & 0.49 & 0.08 & 0.46 & 0.13 & 0.39 & 0.13 & 0.48 & 0.10 \\
\hline 11 & 0.63 & 0.16 & 0.63 & 0.20 & 0.53 & 0.17 & 0.53 & 0.17 & 0.28 & 0.14 & 0.66 & 0.15 \\
\hline 12 & 0.63 & 0.18 & 0.58 & 0.19 & 0.43 & 0.17 & 0.44 & 0.15 & 0.26 & 0.16 & 0.62 & 0.19 \\
\hline 13 & 0.25 & 0.30 & 0.84 & 0.15 & 0.78 & 0.19 & 0.78 & 0.20 & 0.84 & 0.19 & 0.76 & 0.21 \\
\hline 14 & 0.42 & 0.17 & 0.57 & 0.09 & 0.50 & 0.09 & 0.49 & 0.08 & 0.51 & 0.12 & 0.42 & 0.13 \\
\hline 15 & 0.46 & 0.17 & 0.54 & 0.08 & 0.48 & 0.09 & 0.50 & 0.06 & 0.46 & 0.13 & 0.47 & 0.14 \\
\hline 16 & 0.56 & 0.16 & 0.52 & 0.09 & 0.52 & 0.08 & 0.50 & 0.07 & 0.40 & 0.12 & 0.51 & 0.11 \\
\hline 17 & 0.55 & 0.13 & 0.52 & 0.08 & 0.53 & 0.08 & 0.51 & 0.08 & 0.43 & 0.12 & 0.54 & 0.10 \\
\hline \multirow[t]{2}{*}{18} & 0.46 & 0.17 & 0.57 & 0.13 & 0.51 & 0.15 & 0.50 & 0.08 & 0.41 & 0.16 & 0.51 & 0.12 \\
\hline & \multicolumn{2}{|c|}{ Scenario 7} & \multicolumn{2}{|c|}{ Scenario 8} & \multicolumn{2}{|c|}{ Scenario 9} & \multicolumn{2}{|c|}{ Scenario 10} & \multicolumn{2}{|c|}{ Scenario 11} & \multicolumn{2}{|c|}{ Scenario 12} \\
\hline $\begin{array}{l}\text { Qu. } \\
\text { N. }\end{array}$ & Mean & $\begin{array}{l}\text { Std. } \\
\text { Dev. }\end{array}$ & Mean & $\begin{array}{l}\text { Std. } \\
\text { Dev. }\end{array}$ & Mean & $\begin{array}{l}\text { Std. } \\
\text { Dev. }\end{array}$ & Mean & $\begin{array}{l}\text { Std. } \\
\text { Dev. }\end{array}$ & Mean & $\begin{array}{l}\text { Std. } \\
\text { Dev. }\end{array}$ & Mean & $\begin{array}{l}\text { Std. } \\
\text { Dev. }\end{array}$ \\
\hline 1 & 0.63 & 0.15 & 0.62 & 0.13 & 0.54 & 0.12 & 0.45 & 0.14 & 0.49 & 0.07 & 0.64 & 0.19 \\
\hline 2 & 0.63 & 0.22 & 0.65 & 0.21 & 0.40 & 0.18 & 0.34 & 0.15 & 0.40 & 0.19 & 0.71 & 0.20 \\
\hline 3 & 0.67 & 0.18 & 0.69 & 0.15 & 0.61 & 0.15 & 0.59 & 0.17 & 0.61 & 0.15 & 0.55 & 0.25 \\
\hline 4 & 0.63 & 0.17 & 0.69 & 0.17 & 0.46 & 0.17 & 0.45 & 0.16 & 0.53 & 0.18 & 0.55 & 0.27 \\
\hline 5 & 0.48 & 0.14 & 0.48 & 0.07 & 0.45 & 0.12 & 0.44 & 0.18 & 0.38 & 0.13 & 0.59 & 0.15 \\
\hline 6 & 0.63 & 0.19 & 0.69 & 0.16 & 0.51 & 0.15 & 0.49 & 0.16 & 0.58 & 0.16 & 0.53 & 0.22 \\
\hline 7 & 0.63 & 0.13 & 0.66 & 0.18 & 0.50 & 0.15 & 0.50 & 0.13 & 0.53 & 0.13 & 0.44 & 0.19 \\
\hline 8 & 0.66 & 0.17 & 0.69 & 0.15 & 0.48 & 0.14 & 0.49 & 0.14 & 0.53 & 0.15 & 0.53 & 0.20 \\
\hline 9 & 0.65 & 0.17 & 0.66 & 0.16 & 0.49 & 0.12 & 0.49 & 0.14 & 0.54 & 0.13 & 0.54 & 0.20 \\
\hline 10 & 0.52 & 0.11 & 0.55 & 0.12 & 0.45 & 0.12 & 0.39 & 0.14 & 0.44 & 0.16 & 0.55 & 0.17 \\
\hline 11 & 0.62 & 0.17 & 0.69 & 0.14 & 0.46 & 0.13 & 0.41 & 0.13 & 0.52 & 0.17 & 0.71 & 0.20 \\
\hline 12 & 0.62 & 0.18 & 0.68 & 0.15 & 0.40 & 0.13 & 0.39 & 0.16 & 0.55 & 0.19 & 0.71 & 0.18 \\
\hline 13 & 0.65 & 0.24 & 0.80 & 0.20 & 0.82 & 0.18 & 0.82 & 0.20 & 0.84 & 0.17 & 0.57 & 0.32 \\
\hline 14 & 0.51 & 0.16 & 0.53 & 0.10 & 0.45 & 0.12 & 0.46 & 0.12 & 0.54 & 0.08 & 0.54 & 0.16 \\
\hline 15 & 0.52 & 0.09 & 0.55 & 0.11 & 0.46 & 0.08 & 0.48 & 0.11 & 0.53 & 0.10 & 0.52 & 0.16 \\
\hline 16 & 0.56 & 0.11 & 0.56 & 0.12 & 0.47 & 0.10 & 0.46 & 0.08 & 0.47 & 0.11 & 0.59 & 0.17 \\
\hline 17 & 0.55 & 0.10 & 0.53 & 0.10 & 0.47 & 0.09 & 0.49 & 0.09 & 0.46 & 0.12 & 0.59 & 0.15 \\
\hline 18 & 0.56 & 0.12 & 0.62 & 0.13 & 0.48 & 0.06 & 0.45 & 0.15 & 0.48 & 0.13 & 0.55 & 0.18 \\
\hline
\end{tabular}

Increasing the luminance and getting to the 'everything on - bright level' scenario brought a significant $(p<0.05)$ decrease in comfort, pleasantness and safety perception, while increasing the distraction of the driver.

Two comparisons were employed for the evaluation of luminance variations on single lighting elements: doors bright - doors low level (scenarios $3-4$ ) and foot space bright foot space low level (scenarios $9-10$ ). These produced no significant differences in the answer distribution, apart from the brightness assessment in comparison $3-4$ and the impression of space in comparison 9-10.

The comparison between the scenario without ambient lighting and that with the 
Table 7 Statistical significance level for some scenario comparisons for each question. The comparisons are the ones listed in the text (Section 4.1) and are indicated by the numbers at the top of each column. Above them, is indicated the category of the comparison: brightness, colour or position. Highly significant results $(p<0.01)$ are highlighted by dark grey cells. Significant results $(p<0.05)$ are highlighted by light grey cells

\begin{tabular}{rllllllll}
\hline & \multicolumn{3}{l}{ Brightness } & & & \multicolumn{2}{l}{ Colour } & \multicolumn{2}{l}{ Position } \\
\cline { 2 - 4 } Qu. No. & $5-7$ & $7-1$ & $3-4$ & $9-10$ & $5-11$ & $7-12$ & $4-9$ & $4-11$ \\
\hline 1 & 0.002 & 0.493 & 0.147 & 0.007 & 0.026 & 0.710 & 0.945 & 0.130 \\
2 & 0.001 & 0.509 & 0.958 & 0.152 & 0.003 & 0.099 & 0.011 & 0.034 \\
3 & 0.001 & 0.097 & 0.549 & 0.878 & 0.005 & 0.148 & 0.165 & 0.871 \\
4 & 0.001 & 0.076 & 0.135 & 0.944 & 0.003 & 0.456 & 0.008 & 0.700 \\
5 & 0.001 & 0.001 & 0.004 & 0.747 & 0.112 & 0.002 & 0.253 & 0.002 \\
6 & 0.001 & 0.012 & 0.123 & 0.794 & 0.005 & 0.096 & 0.004 & 0.699 \\
7 & 0.001 & 0.001 & 0.270 & 0.731 & 0.009 & 0.001 & 0.005 & 0.168 \\
8 & 0.001 & 0.092 & 0.702 & 0.702 & 0.022 & 0.023 & 0.020 & 0.133 \\
9 & 0.001 & 0.136 & 0.277 & 0.592 & 0.011 & 0.042 & 0.001 & 0.032 \\
10 & 0.002 & 0.322 & 0.103 & 0.063 & 0.126 & 0.201 & 1 & 0.983 \\
11 & 0.001 & 0.475 & 0.808 & 0.288 & 0.001 & 0.064 & 0.058 & 0.597 \\
12 & 0.001 & 0.456 & 0.628 & 0.726 & 0.001 & 0.007 & 0.183 & 0.022 \\
13 & 0.002 & 0.001 & 0.562 & 0.955 & 0.325 & 0.187 & 0.241 & 0.116 \\
14 & 0.658 & 0.047 & 0.938 & 0.919 & 0.474 & 0.218 & 0.144 & 0.099 \\
15 & 0.185 & 0.166 & 0.921 & 0.337 & 0.014 & 0.656 & 0.047 & 0.098 \\
16 & 0.001 & 0.203 & 0.271 & 0.649 & 0.025 & 0.141 & 0.085 & 0.032 \\
17 & 0.001 & 0.777 & 0.319 & 0.837 & 0.052 & 0.056 & 0.203 & 0.013 \\
18 & 0.001 & 0.042 & 0.616 & 0.146 & 0.081 & 0.563 & 0.154 & 0.987 \\
\hline
\end{tabular}

centre console illumination (scenarios 5 - 11) is also interesting, because the latter represents the minimal ambient lighting that can be found in today's series-production cars. This kind of illumination provided better interior attractiveness and functionality $(p<0.01)$ and improved perceived interior quality and space perception $(p<0.05)$. This means that a minimum quantity of light in the car interior constitutes already a considerable advantage, regarding the subjective perception, in comparison to dark.

\subsubsection{Effects of colour}

Two particular scenarios were assessed, which provided the same luminance level and same light positions, but different colours: orange and blue (scenarios 7-12).

It could be verified that the blue lighting appeared brighter than the orange and facilitated the finding of control elements, although being uncomfortable $(p<0.01)$.
Orange light colour looked more luxurious and gave a better quality perception $(p<0.05)$.

\subsubsection{Effects of position}

Three different lighting positions were evaluated: doors, centre console and foot space (scenarios 4-9-11). The differences between these three scenarios were quite small although several significant differences were found. The foot space lighting obtained slightly lower assessments than the other two illumination positions. Compared to door lighting, foot space lighting (scenarios 4 -9) gave a worse perception of the whole car interior, complicated concentration $(p<0.05)$ and was found to be cheaper, less comfortable and less pleasant $(p<0.01)$. Compared to centre console lighting, door lighting (comparison $4-11$ ) was assessed to be brighter $(p<0.01)$, allowed a better perception of the car interior, looked more luxurious and had an activating effect, while complicating the finding of controls $(p<0.05)$. 


\subsection{Effects on driver's emotional state}

The results obtained from the SAM test showed two aspects. On one hand, there was quite a wide variance of the answers on the pleasure and arousal axes, probably due to the different sensations and feelings which animated the different participants, independently from the test and the tested scenarios. On the other hand the answers on the dominance axis concentrated more on the middle point, this effect being explained by the apparently difficult the participants had in understanding this dimension.

In order to understand the change in the emotional state of the participants, each scenario rating was compared to the answer given at the beginning of the experiment. The difference between these two ratings gave a dimension of the emotional change caused by the scenario $\left(\Delta P=P-P_{0} ; \Delta A=A-A_{0}\right.$; $\Delta D=D-D_{0}$, where $P_{0}, A_{0}, D_{0}$ are the values of PAD gathered at the beginning of the test).

The differences distributions are displayed in Figures 7, 8 and 9 in the form of boxplot graphs. In these graphs the lower and upper edges of the box display respectively are the first and third quartiles of the answer distribution. The solid line inside the box indicates the median, while the two whiskers above and underneath the box display maximum and minimum values. The additional hollow dots indicate outliers while asterisks represent extreme outliers.

Small changes can be seen in the dimensions of arousal and dominance (Figures 8 and 9), while in the pleasure dimension (Figure 7) the distribution is wider though the median value remains zero in most cases. Moreover, this result should not be taken to mean there is a negative trend in the effect of ambient lighting: Many participants judged their state at the beginning already to be 'happy' (values 1 and 2 on the pleasure dimension) and therefore there was no room for improvement in the ratings after experiencing the ambient lighting.

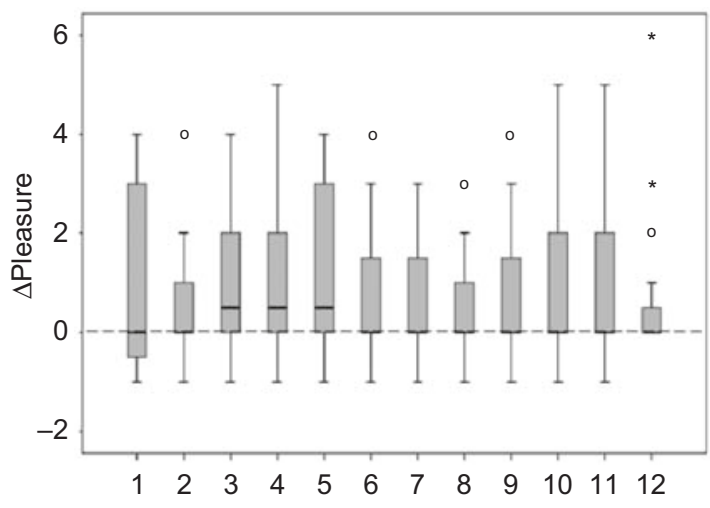

Figure 7 Boxplot graph of the distribution of the difference in the Pleasure rating between each scenario and the answer at the beginning of the experiment

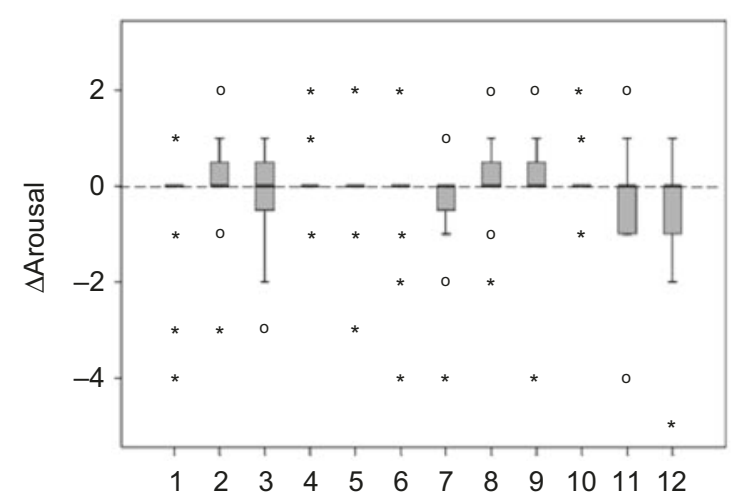

Figure 8 Boxplot graph of the distribution of the difference in the Arousal rating between each scenario and the answer at the beginning of the experiment

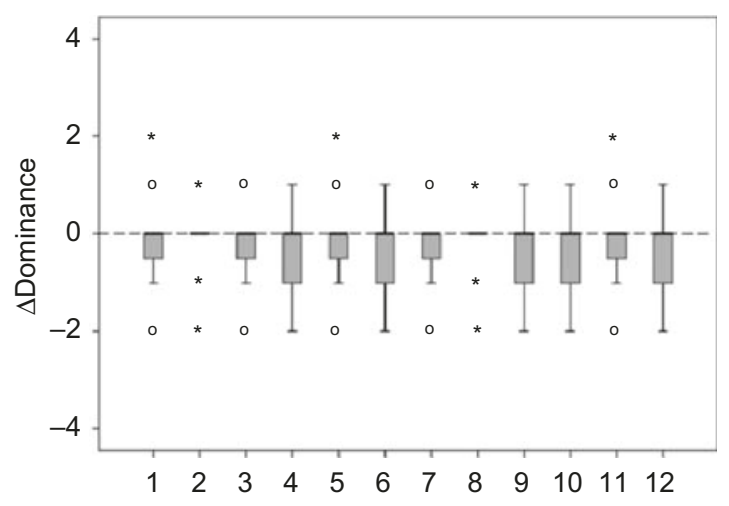

Figure 9 Boxplot graph of the distribution of the difference in the Dominance rating between each scenario and the answer at the beginning of the experiment 
The data were analysed through a Friedman-test with a significance level of $p=0.05$. No statistically significant effect could be found on any of the three dimensions. This has probably been caused by the short time (3 minutes) in which the participants tested each form of ambient lighting added to the low luminances (maximum $1 \mathrm{~cd} / \mathrm{m}^{2}$ ) and mostly peripheral positions.

\subsection{Effects on driver's performance}

During the whole experiment the following data was collected by the simulator system: elapsed time, car position $(\mathrm{x}, \mathrm{y}, \mathrm{z})$,

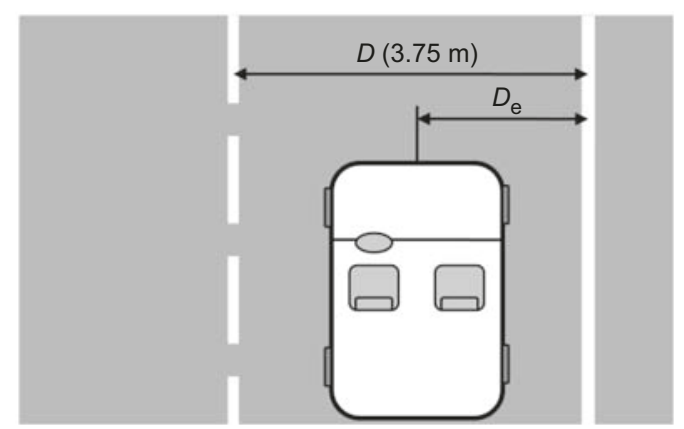

Figure 10 Distance from the edge of the lane, as measured on the simulator. The measure was taken from the middle of the car bumper to the virtual white line on the right side of the road absolute velocity, steering wheel angle, road curvature, distance from the road's edge and covered distance. Every parameter was collected with a frequency of $25 \mathrm{~Hz}$.

The primary driver's task was to drive in the middle of the right lane of a three-lane highway, following another vehicle. The aim of the task was to focus the driver's attention on the road, thus enabling him to perceive ambient lighting only peripherally and through the secondary tasks.

These secondary tasks were designed to make the driver aware of the utility of the ambient lighting in recognizing controls and objects inside the car. Without proper lighting the drivers might not be able to push the right button, or find the control for the air nozzle.

Since the drivers could not accelerate or brake, the only parameter indicative of driving performance is the distance from road's edge $\left(D_{\mathrm{e}}\right)$, measured in metres (Figure 10). The standard deviation of this measure $\sigma\left(D_{\mathrm{e}}\right)$, evaluated over the whole 3 minutes experimental run, is indicative of the driver's performance in following the lane in a specific lighting scenario.

This data, shown in Figure 11, has been normalised $\left(\sigma\left(D_{\mathrm{e}}\right)\right.$ for scenario 5 was considered as 1) and then analysed through a

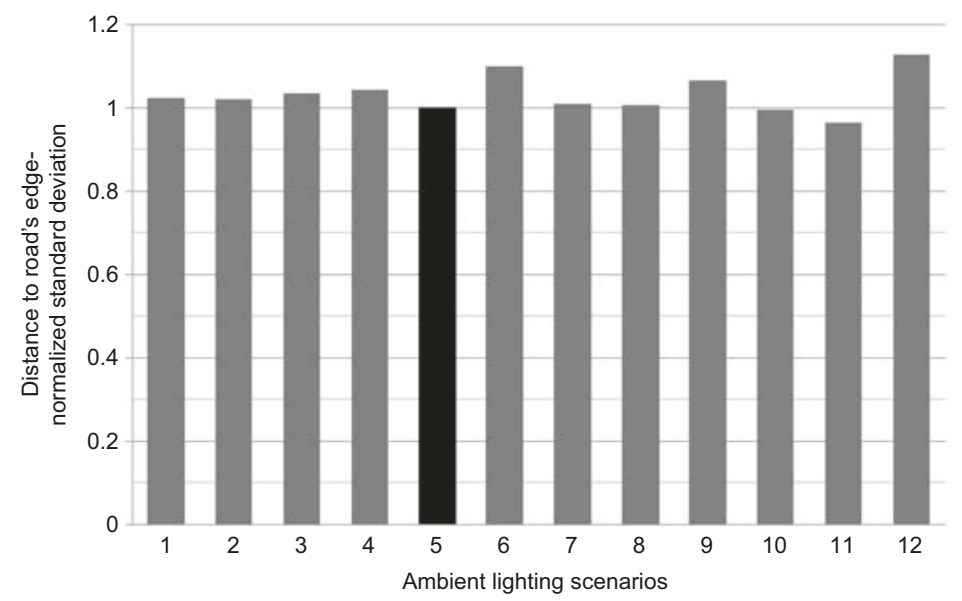

Figure 11 Values of $\bar{\sigma}\left(D_{\mathrm{e}}\right)$ in relation to lighting scenarios. Scenario number 5 (highlighted) is the scenario without ambient lighting for which the value is normalised to 1 
one-way ANOVA for the ambient lighting scenarios. The results showed no significant effect of ambient lighting on driving performance $(\mathrm{F}=0.435 p=0.939)$.

However, since this measure was not the primary goal of the research, it is difficult to assess its importance. Certainly, the driver's performance has not been influenced either way by the ambient lighting scenarios. It might be possible to get a significant result for this measure by extending the duration of each experimental run. However, it is realistic to believe that driver fatigue would have a larger influence than ambient lighting on such a measurement.

\section{Conclusion}

The presented study showed significant effects of ambient lighting on driver's perception. In particular the advantages of ambient lighting concerning space perception, functionality and perceived interior quality were clearly stated, even at low luminances. These advantages are not enhanced by simply using more brightness or by employing more light sources.

The main conclusions which can be drawn from this experiment are:

- The whole perception of the car interior is improved through the use of ambient lighting while driving. It intensifies the space perception, enhances the perceived quality of materials and design, facilitates the finding of controls and the orientation in the car, and improves perceived safety.

- A small number of light sources placed in order to cover the whole field of view can give equal results, in terms of perceived space and quality, as many overlapping light sources. This can be seen, for example, by comparing the scenarios with and without accents. Thus, aimed ambient lighting can use fewer components and reduce the production costs while creating a welcoming pleasant atmosphere in the car interior. - A higher luminance (mean values of $0.04 \mathrm{~cd} / \mathrm{m}^{2}$ ), while increasing the chance of creating discomfort glare and distraction during the driving, does not bring improvements to the driver's perception of the car interior or a better orientation and functionality. This means that less expensive light sources with a lower light output can achieve the same comfort effects.

- The influence of different colours is to affect more criteria in different ways. This has several causes: The diverse field of view and brightness of each colour when mesopically adapted (blue is perceived as brighter and over a wider angle than orange or red), the various emotional values and the different interaction with interior materials through reflection. Thus, the choice of colour for ambient lighting has to meet many requirements and is certainly important for brand identity and design compliance.

- The effects on the emotional state could not be verified, probably due to the short time available for the evaluation and the focus that the drivers gave to the primary driving task. In other research studies, where the light stimuli constituted the main focus and the test was longer, such effects might be verified. Probably in order to discover more on this particular aspect, a different experimental design would have to be employed.

- The driver's overall performance was not influenced by the ambient lighting, although this measure only assessed how the drivers followed the lane line. No measurements were made on visual performances, since these have been already verified in other studies. ${ }^{2,4}$. These results can be considered and used in the future development of such illumination systems, in order to optimize their design, reduce costs and energy consumption and to achieve an optimal subjective perception for drivers. 
On a practical level, from the investigated scenarios a guideline for developers and manufacturers, suggesting luminances and their tolerance ranges for ambient lighting systems will be derived.

Further research should enlarge the spectrum of the investigated colours, which in this study was limited to only orange and blue. This comparison alone, although juxtaposing short wave and long wave colours, cannot describe completely all the possible effects that different lighting hues have on the driver's perception of space and quality. In this perspective, the influence of the interior materials is also important. Indeed, the most of the ambient lighting comes to the eye after the reflection from completely different kinds of material (e.g. from black plastics to beige or white leather). Thus, the perceived situation should be considered not only as a function of the light colour but also of the combination lighting-material. This topic is currently being investigated.

Since ambient lighting has a functional impact and not only an emotional one, its influence on the execution of the secondary tasks (e.g. finding and pressing buttons and controls, picking up things, using information devices such as satellite navigation) should be investigated with objective measurements and not only through the subjective assessments used in this study.

Moreover, dynamic interior lighting changes (in brightness, position and colour) and their effects have to be investigated. A further step in this direction will be the connection of these changes with inputs from the environment, the car and the passengers. This will provide, on the one hand, adaptation of the interior lighting to the surrounding conditions and to the vehicle settings, enhancing safety and possibly giving a visible feedback of the car's status, and, on the other hand, flexibility and compliance to the customers' individual tastes. The advantages and problems arising from such systems, as well as their acceptance by drivers, have still to be tested and verified. Nevertheless, they offer a new, interesting, emotional and much more coloured way of understanding and developing vehicle interior lighting.

\section{References}

1 Wördenweber B, Wallaschek J, Boyce P, Hoffman DD. Automotive Lighting and Human Vision. Berlin: Springer Verlag, 2007.

2 Grimm M. Requirements for an Ambient Interior Lighting System for Motor Vehicles. München: Herbert Utz Verlag, 2003.

3 Schellinger S, Dorit F, Klinger K, Lemmer U. Advantages of ambient interior lighting for drivers contrast vision: Proceedings of the SPIE 6198: Photonics Europe: Photonics in the Automobile, 61980G, Strasbourg: 2006.

4 Karsten K, Lemmer U. The influence of ambient light on the driver: Optical Sensors 2008, Proceedings of the SPIE, Strasbourg, France: 2008: 700329.1-700329.4.

5 Devonshire J, Flannagan M. Effect of automotive interior lighting on driver vision. UMTRI, Ann Arbor: University of Michigan; 2007.

6 Olson P. The effect of vehicle interior lighting systems on driver sight distance. UMTRI, Ann Arbor: University of Michigan; 1985.

7 Küller R, Ballal S, Laike T, Mikellides B, Tonello G. The impact of light and colour on psychological mood: a cross-cultural study of indoor work environments. Ergonomics 2006; 49: 1496-1507.

8 McCloughan C, Aspinall P, Webb R. The impact of lighting on mood. Lighting Research and Technology 1999; 31: 81-88.

9 Greule R. Emotionale Wirkung von farbiger LED-Beleuchtung im Innenraum. Hamburg: Hochschule für Angewandte Wissenschaften (HAW) Hamburg; 2007.

10 Houser K, Tiller D. Measuring the subjective response to interior lighting: paired comparisons and semantic differential scaling. Lighting Research and Technology 2003; 35: 183-198.

11 Veitch J, Newsham G, Boyce P, Jones C. Lighting appraisal, well-being and performance in open-plan offices: A linked 
mechanisms approach. Lighting Research and Technology 2008; 40: 133-151.

12 Huesmann A, Ehmanns D, Wisselmann D. Development of ADAS by means of driving simulation: Proceedings of the Driving Simulation Conference Europe, Paris: 2006: 131-141.

13 European Standard EN 13201-2, Road Lighting - Performance Requirements. 2003.

14 Illuminating Engineering Society of North America. ANSI/IESNA RP-8-00 - American National Standard for Roadway Lighting. 2005.

15 Commission Internationale de l' Eclairage. Road Transport Lighting for Developing Countries. CIE Technical Report 180:2007. Vienna: CIE; 2007.

16 Damasky J. Lichttechnische Entwicklung von Anforderungen an Kraftfahrzeugscheinwerfer. München: Herbert Utz Verlag, 1995.

17 Ekrias A, Guo L, Eloholma M, Halonen L. Intelligent road lighting control in varying weather conditions. Light and Engineering 2008; 16: 72-78.

18 Ishihara S. Tests for Colour-Blindness Tokyo. Kyoto: Kanehara Shuppan Co., 1979.

19 OSRAM Opto Semiconductors. www.osram.de. [Online] 2009 Retrieved 15 December 2009, from: http://catalog.osram-os.com/catalogue/ catalogue.do;jsessionid $=799185$ CEA27445C96 FE3ED1E18010931?favOid $=0000000$ 20001c0b700030023\&act $=$ showBookmark.

20 Lang P. Behavioural treatment and biobeavioural assessment: computer applications. In Sidowski J, Johnson J, Williams T, editors. Technology in Mental Health Care Delivery Systems. Norwood, NJ: Ablex, 1980: pp. 119-137.

21 Mehrabian A, Russell JA. An Approach to Environmental Psychology. Cambridge, MA: MIT, 1974.

22 Mehrabian A. Basic Dimensions for a General Psychological Theory. Cambridge, MA: O,G\&H, 1980.

23 Valdez P, Mehrabian A. Effects of color on emotion. Journal of Experimental Psychology 1994; 123: 394-409.

24 Fleischer S, Krueger H, Schierz C. Effects of brightness distribution and light colours on office staff: Lux Europa 2001 - Proceedings of the Conference: Reykjavik, 2001: 76-80.

25 Bradley MM, Lang PJ. Measuring emotion: the self-assessment manikin and semantic differential. Journal of Behavior Therapy and Experimental Psychiatry 1994; 25: 49-59. 